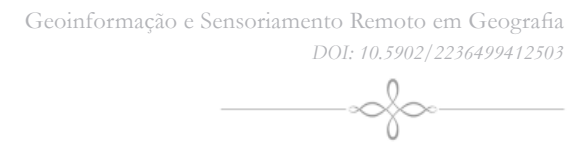

\section{Técnicas de geoprocessamento aplicadas na classificação e avaliação da distribuição das espécies arbóreas nas praças de Buritizeiro/MG}

Samuel Ferreira da Fonseca* Danniella Carvalho dos Santos** Wallace Magalhães Trindade***

* Graduado em Geografia pela Universidade Estadual de Montes Claros (UNIMONTES). Mestrando em Produção Vegetal na Universidade Federal dos Vales do Jequitinhonha e Mucuri (UFVJM).

** Graduada em Geografia pela UNIMONTES. Mestranda em Geografia na Universidade Federal de Uberlândia (UFU).

\footnotetext{
*** Mestre em Geologia pela Universidade Federal de Minas Gerais (UFMG). Doutorando em Geografia na mesma universidade.
}

Palavras-chave:
Arborização urbana,
geoprocessamento, SIG.
Key-Words: forestry.
Urban Geoprocessing, GIS
geros

Geografia Ensino \& Pesquisa, vol. 18, n. 2, maio/ago. 2014.

\begin{abstract}
The objective of this study is to assess the spatial distribution of tree species in the public squares of the city Buritizeiro - MG and the relationship of these species with the local population, with the electricity network and its positioning by traffic signs using GIS . The methodological procedures were: literature review of books, websites and papers trying to elucidate the concepts inherent in the theme . There were two field campaigns, in which the recognition of tree species found in the survey squares and plant health of trees occurred. In the final step thematic maps on the distribution of each species found in the overlying Plant City, which was on the geo-referenced map of the IBGE census tract using ArcGIS 9.3 software squares were generated., Map Number of Individuals per Square; Map General Average DAP; Map of Plant Location and Map of Conflicts between trees and Signaling Traffic Map of Predominant Species: The following maps were produced. This study allowed visualization aspects of afforestation of squares in Buritizeiro such as low range of species per square DBH of individual trees, plant health status among other variables. Highlighting the low interference related to the transit system and the absence of interference in the electricity distribution network plus point. It is concluded that studies on GIS in urban forestry empower decision making because the accuracy of the techniques, which enables better understanding of the problems arising from the maintenance of urban green.
\end{abstract}




\section{Introdução}

De acordo com Câmara et al., (2001) o agrupamento de várias informações a respeito de uma determinada localidade ou fenômeno sempre foi uma das importantes atividades das sociedades organizadas. Conforme os autores tais serviços se realizavam de modo convencional, ou seja, por meio de mapas em papel, impedindo a realização de análise que combinasse uma abordagem mais ampla e consistente. Foi, portanto, através do desenvolvimento das técnicas de informática, permitindo representar dados geográficos em ambiente computacional que emergiu o Geoprocessamento.

Nestes termos, Geoprocessamento é compreendido como resultado da interação de técnicas matemáticas e computacionais com a finalidade de tratar a informação geográfica/espacial. Sendo uma das ferramentas de grande relevância pertencentes à Ciência Geográfica (CÂMARA et al., 2001). Possui vasta potencialidade quanto à aplicação, em análises espaciais, planejamento urbano e rural, bem como apoio a tomada de decisão envolvendo uma infinidade de temas e objetos de estudo.

Dentre as aplicabilidades do geoprocessamento se destaca o uso em inventários arbóreos destinados ao ambiente urbano. Nesse sentido, conforme Franco (2006), a utilização do Geoprocessamento está muito além das outras maneiras de gerenciamento do patrimônio verde. A referida autora realizou um trabalho de cadastro e controle de indivíduos arbóreos na Universidade Federal de Minas Gerais - UFMG, Campus-Pampulha em Belo Horizonte/MG, demonstrando a eficiência do uso bem direcionado das técnicas de geoprocessamento para áreas urbanas. Schuch (2006) utilizou geoprocessamento visando apresentar os padrões da arborização urbana do município de São Pedro do Sul/RS, apresentando as interferências causadas na vegetação citadina em função das ações antrópicas no meio urbano.

Ao analisar o uso de Geoinformação no inventário de arborização de ruas em Curitiba/ PR, Lima Neto (2011), confere a essas técnicas confiabilidade, precisão e potencial de atualização consistente dos dados em ambiente SIG, mostrando a magnitude do Geoprocessamento e sua aplicação em estudos referentes a áreas verdes urbanas.

Em estudos urbanos a aplicação das técnicas mencionadas permite levantar dados que podem auxiliar na gestão e manejo do ambiente visando melhores formas no relacionamento entre os habitantes e os recursos naturais. De acordo com Schuch (2006) os aspectos da arborização dos espaços urbanos são fundamentais para manter o ambiente da cidade equilibrado. No mapeamento de situação fitossanitária, conflitos com rede de eletricidade ou com a sinalização de trânsito, a utilização das técnicas de Geoprocessamento assume papel fundamental para o manejo das áreas verdes das praças de Buritizeiro. Mediante a implantação de tais técnicas informatizadas, o município passa a ser favorecido ao possuir o patrimônio verde identificado e monitorado.

O objetivo fundamental deste trabalho consiste na avaliação da arborização nas áreas verdes urbanas quanto à distribuição, composição e fitossanidade enfocando as praças públicas da cidade de Buritizeiro - MG e a relação dessas espécies com a população local, com a rede de eletricidade e seu posicionamento mediante a sinalização de trânsito.

Geografia Ensino \& Pesquisa, v. 18, n.2, p. 109-122, maio/ago. 2014

Técnicas de geoprocessamento aplicadas na classificação e distribuição das espécies arbóreas nas praças de Buritizeiro/MG
Localização e caracterização da área de estudo

O município de Buritizeiro está inserido na mesorregião administrativa Norte de Minas Gerais (Figura 1) possui $7.236 \mathrm{~km}^{2}$ de área e está a $364 \mathrm{~km}$ de distância da capital Belo Horizonte (IBGE, 2012). Possui por limítrofes os seguintes municípios: Pirapora, João Pinheiro, Ibiaí, Lagoa dos Patos, Santa Fé de Minas, Lassance, São Gonçalo do Abaeté, Barreiro Grande e Várzea da Palma (VIANA, 2006). 
Figura 1 - Localização de Buritizeiro na mesorregião Norte de Minas.

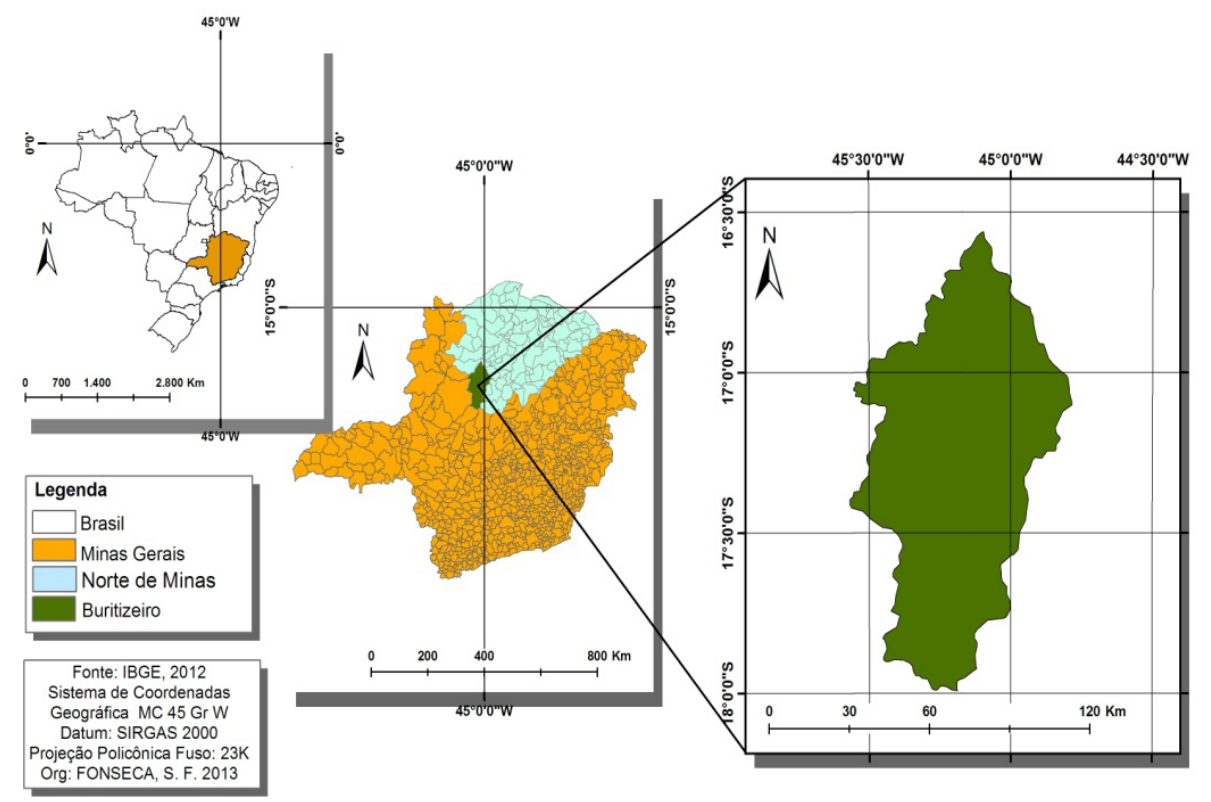

Fonte: IBGE, 2012. Org: FONSECA, S. F. 2013

De acordo com o IBGE, (2012) a população rural atual corresponde a 3.292 pessoas, o que equivale a $12,5 \%$ de um total de 26.297 habitantes. Fator este que mostra o adensamento dos aglomerados urbanos em detrimentos da população das áreas rurais do município. Que, embora seja considerado de pequeno porte, o que facilita o planejamento estratégico, acompanha a tendência sugerida pela ONU Organização das Nações Unidas, que aponta as pequenas cidades como atrativas e que tenderá a triplicar a população até 2050. (BAENINGER, 2003).

Quanto aos aspectos geológicos, na área urbanizada afloram rochas Neoproterozóicas, (Formação Três Marias - Grupo Bambuí) ocorrendo principalmente na drenagem do Córrego das Pedras e, o Cenozóico é representado pelas Coberturas Detrito-lateríticas Ferruginosas e depósitos Aluvionares Antigos (FONSECA \& SANTOS, 2011; FONSECA, 2012). Na área de estudo são identificadas as seguintes classes de solos: Neossolos litólicos; Latossolos; Neossolos quartzarenicos profundos; Latossolo Vermelho - amarelo e Cambissolo (CETEC, 2008). Na área urbana ocorrem predominantemente os neossolos flúvicos devido à localização marginal do município (margem esquerda do Rio São Francisco). O tipo climático do município de Buritizeiro corresponde ao Clima Tropical Úmido Subúmido do tipo AW de acordo com a classificação de Köppen (1948). O mesmo é caracterizado por invernos secos e frios, bem como verões quentes e chuvosos (FONSECA \& SOUZA, 2011). Segundo Brito, (2009) o índice pluviométrico deste município, varia entre 900 e $1.200 \mathrm{~mm} /$ ano, enquanto a temperatura abrange $22^{\circ} \mathrm{C}$ e $24^{\circ} \mathrm{C}$ no período mais quente e $18^{\circ} \mathrm{C}$ e $19^{\circ} \mathrm{C}$ nos meses mais frios. Ressaltando que as chuvas geralmente não são regulares.

Quanto à vegetação, são raras as manifestações de vegetação nativa, ocorrendo, vez por outra, em loteamentos ainda não ocupados e nas praças. De maneira restrita, observa-se a ocorrência de espécies como Pequizeiros (Caryocar brasiliense Camb) e Embaúbas (Cecropiapalmata Willd).

As praças estudadas nesse trabalho são: Imaculada Conceição; Paulo Machado; Coronel José Geraldo; Beira Rio; Bento de Melo; Praça do Ferro Velho e da Bíblia. As áreas investigadas se encontram totalmente inseridas no núcleo urbano de Buritizeiro/MG estando, portanto, sujeita a dinâmicas multivariadas, isto é são realizadas novas configurações espaciais através da criação de novos estabelecimentos, novos bairros, novas ruas, quase sempre sem o devido planejamento. Atualmente $89 \%$ da população reside na área urbana de Buritizeiro, impedindo a existência de amplas e numerosas áreas verdes como praças e parques de tamanho significativo.

Geografia Ensino \& Pesquisa, v. 18, n.2, p. 109-122, maio/ago. 2014.

Fonseca, S. F. da; Santos, D. C. dos; Trindade, W. M. 


\section{Métodos, técnicas e materiais}

A metodologia adotada para elaboração deste trabalho consistiu em: revisão bibliográfica em livros, sites e artigos científicos buscando elucidar os conceitos inerentes à temática principalmente em manuais de Arborização urbana tais como: Prefeitura Municipal de Sorocaba - SP (2009), Pivetta e Silva Filho (2002), Dantas e Souza (2004) enquanto as questões relacionadas ao Geoprocessamento recorremos à Fitz (2010), Rosa (2009), Câmara et al., (2001) e Florenzano (2011).

Foram realizadas duas campanhas de campo, nas quais realizou-se o reconhecimento das espécies arbóreas encontradas nas praças e levantamento da situação fitossanitária das árvores obedecendo aos critérios estabelecidos por Schuch, (2006, p. 52) que sugere: i) Bom: indivíduo plenamente vigoroso, sem sinais de ataques de pragas, doenças ou injúrias mecânicas; ii) Razoável: indivíduo com boas condições gerais de saúde podendo apresentar algum sinal de deficiência superficial, ataque de pragas ou doenças, ou injúria mecânica superficial; e iii) Ruim: indivíduo em estado avançado de declínio ou em estado de morte eminente.

Utilizou-se registro dos nomes populares de cada espécie e, posteriormente com o aporte da literatura sobre a temática ocorreu a sistematização dos dados em uma tabela onde foi identificado o nome popular e o científico, DAP e localização de cada espécie. Para determinação do DAP foram realizadas as medições com fita métrica e, posteriormente utilizando a Equação 1.

$$
D A P=\frac{C A P}{\pi}
$$

\section{Equação 1}

Onde DAP representa o Diâmetro a Altura do Peito, CAP a Circunferência a Altura do Peito e valor de $\pi 3,1416$. Convencionalmente a CAP é adquirida a 1,3 m do solo (HIGUCHI et al., 2008; BATISTA et al., 2012). Neste trabalho utilizou-se de fita métrica para aferir a CAP e realizou a divisão dos valores por $\pi$, obtendo os valores do DAP nas praças estudadas, exceto a Praça da Bíblia, a qual não apresentou nenhum indivíduo com CAP superior a $15,7 \mathrm{~cm}$, isto é, com DAP maior que $5 \mathrm{~cm}$, o que é recomendado pelo Manual da ESALQ da USP.

Para analisar as situações de conflito entre a arborização das praças, o sistema de transito e entre a rede de distribuição de energia elétrica utilizou os parâmetros da Secretaria Municipal de Meio Ambiente. Esta secretaria estabelece que são consideradas situações conflitantes todas aquelas que estão em desacordo com algum parâmetro estabelecido pela mesma.

A Planta Municipal disponibilizada pela Prefeitura Municipal de Buritizeiro - PMB serviu de mapa base para o presente trabalho, bem como o mapa de setores censitários disponível no sitio do IBGE com escala original de 1/30.000. No primeiro momento foi

Geografia Ensino \& Pesquisa, v. 18, n.2, p. 109-122, maio/ago. 2014.

Técnicas de geoprocessamento aplicadas na classificação e distribuição das espécies arbóreas nas praças de Buritizeiro/MG realizada a transformação dos dados de entrada (Planta Municipal) em formato DWG em para o formato Shapefile (vetorial) e criada uma tabela de atributos. A partir disso foram gerados os mapas temáticos a respeito da distribuição de cada espécime encontrado nas praças sobrepostos a Planta Municipal, a qual foi georreferenciada sobre o mapa dos setores censitários do IBGE utilizando o software ArcGIS versão 9.3. Foram elaborados os seguintes mapas: Mapa de Espécies Predominantes; Mapa de Quantidade de Indivíduos por Praça; Mapa de Média Geral de DAP e Mapa de Situação Fitossanitária. 


\section{Resultados e discussões}

A partir da metodologia adotado neste trabalho foi possível compreender a diversidade e distribuição das espécies arbóreas na praças selecionadas.

Foi identificada uma sequência de arvores da espécie Licania tomentosa Benth (Oitizeiro) utilizada como arborização de via pública. Em função do porte da espécie, do formato de copa, da não condução do crescimento dos indivíduos por meio técnicas de poda, aponta-se problemas associados à iluminação e sinalização do trânsito. (Figura 2).

Figura 2 - Foto da rua arborizada com "Oitizeiras”. Observa a situação conflitante entre arborização e iluminação pública. Em destaque (seta) a presença de poste de iluminação.

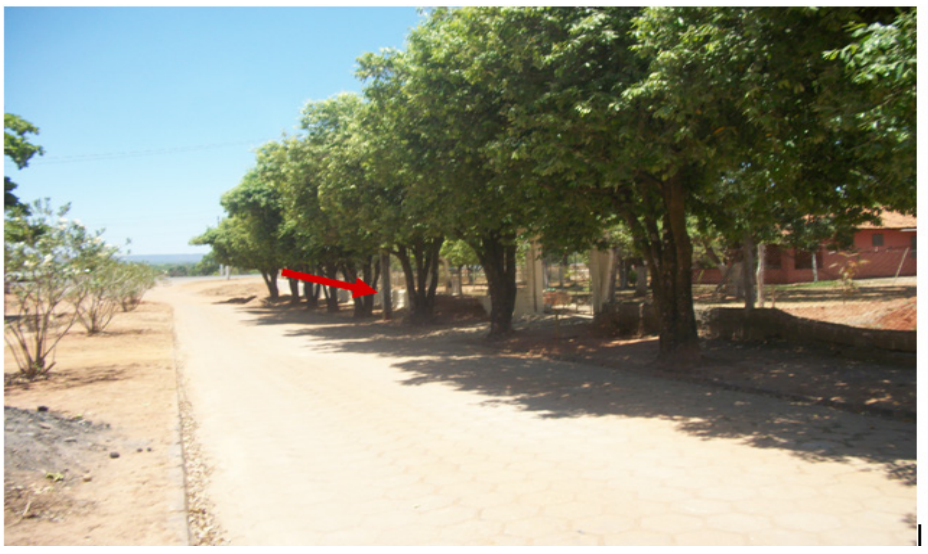

Fonte: fotografia de FONSECA, S. F. 2012.

O município possui um plano de orientação para arborização urbana, organizado pela Secretaria de Meio Ambiente (MENDONÇA, et al., 2009). Esse documento apresenta as diretrizes que visam à implantação da vegetação na cidade de forma racional. A Tabela 1 abaixo integra o Manual de Orientação para Arborização Urbana.

Tabela 1 - Relação das diretrizes para arborização urbana de Buritizeiro, MG.

\section{Diretrizes para Arborização Urbana}

\section{Medidas observadas Distâncias (m)}

Recuo mínimo da muda em relação ao meio-fio $\quad 0,50$

Distâncias mínimas entre árvore e entradas de garagem $\quad 1,00$

Vão livre entre a copa das árvores e a rede de baixa tensão $\quad 1,00$

Vão livre entre a copa das árvores e a rede de alta tensão $\quad 2,00$

Altura máxima das árvores de pequeno porte $\quad 4,00$

Altura máxima das árvores de médio porte $\quad 6,00$

Distância mínima entre árvores de pequeno porte e placas $\quad 5,00$

de sinalização

Distância mínima de árvores de médio porte e placas de $\quad 7,00$

sinalização

Distância mínima das esquinas

7,00

Fonte: Mendonça, et al. 2009. A tabela foi elaborada em 2009 contendo as medidas que regulamentam o plantio de árvores tanto por particulares quanto pela própria prefeitura.

Os últimos dois itens são de suma importância em razão da interferência direta na dinâmica Geografia Ensino \& Pesquisa, v. 18 n.2, p. 109-122, maio/ago. 2014 
diversidade de espécies (MENDONÇA et al. 2009; SANTOS \& TEXEIRA, 2001; PIVETTA \& SILVA FILHO, 2002). A diversidade de espécies estabelece a beleza paisagística urbana de forma que, permite a permanência de flores, frutos e beleza cênica durante o ano todo. A Figura 3 apresenta o mapa de número de espécies em cada uma das áreas verdes estudadas.

Figura 3 - Mapa da área urbana de Buritizeiro, MG. Os círculos representam a ocorrência de espécies predominantes nas áreas verdes estudadas

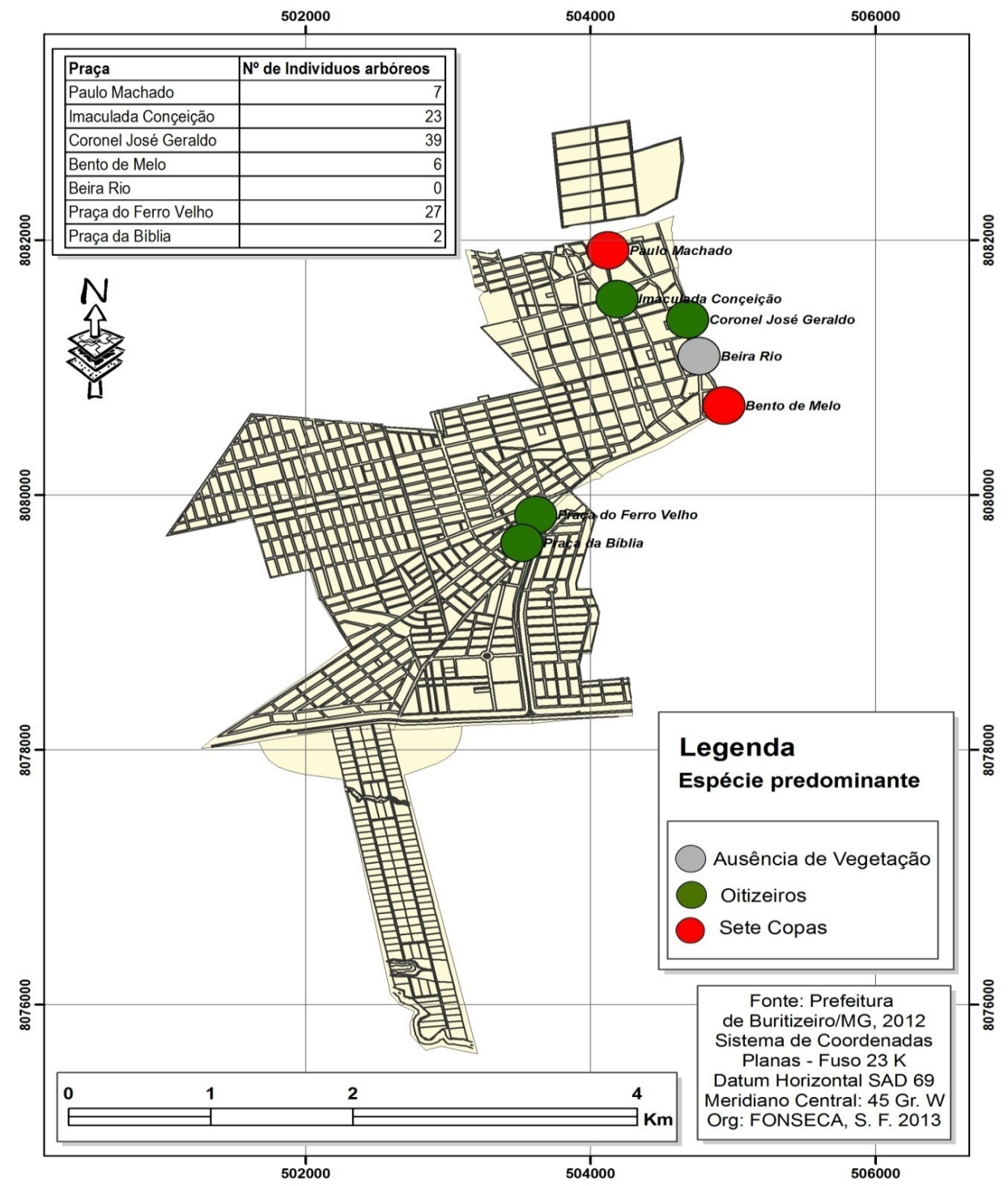

Fonte: organizado por FONSECA, S. F. (2013).

Geografia Ensino \& Pesquisa, v. 18, n.2, p. 109-122, maio/ago. 2014.

Técnicas de geoprocessamento aplicadas na classificação e distribuição das espécies arbóreas nas praças de Buritizeiro/MG

Como notamos no mapa acima, a oitizeira (Licania tomentosa), representa a espécie predominante na maioria das praças estudadas. Assim como, Sete copas (Terminalia catappa spp.), figurou como segundo colocado, estando predominantemente em duas praças.

$\mathrm{Na}$ área de estudo, as espécies exóticas refere-se àquelas que não condizem com o Bioma local, nesse caso as oitizeiras e as sete copas. Para Batistel et al. (2009) o uso destas implica na descaracterização das paisagens e pode prejudicar áreas de ocorrência de vegetação natural presentes nos ambientes urbanos. De acordo com os mesmos autores o uso exacerbado de oitizeiro (Licania tomentosa) reflete a ausência de um planejamento urbano em prol da arborização local. Percebeu-se, a presença predominante dessa espécie na maioria das praças estudadas. 
A oitizeira (Licania tomentosa), embora seja nativa no país, sendo encontrada na Mata Atlântica, nas áreas analisadas essa espécie é exótica, posto que o município está inserido no bioma Cerrado. Conforme Batistel et al., (2009) o ideal no planejamento da arborização urbana é a integração flora-fauna nativa e a ênfase na vegetação nativa representa uma contribuição no sentido da melhoria da biodiversidade e da valorização de referenciais ecológicos e paisagísticos.

Abaixo, na Figura 4, são apresentadas duas situações onde ocorrem, respectivamente, predominância de Oitizeiras e Sete Copas.

Figura 4-Fotos das áreas verdes: a) Praças Imaculada Conceição (A esquerda), presença predominante de oitizeiros e b) Bento de Melo(presença de Sete Copas)
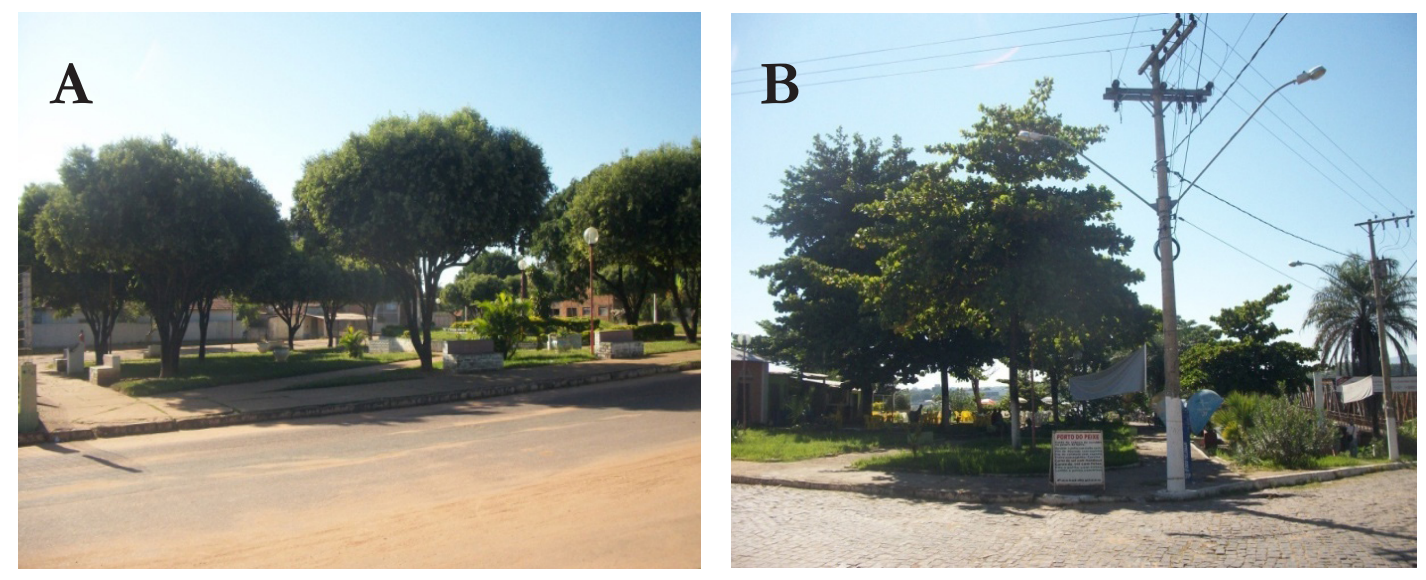

Fonte: fotografias de FONSECA, S. F. 2013.

A presença de uma única espécie por praça não é o ideal, no entanto, controlar tal situação, bem como, reorganizar a arborização das mesmas é tarefa complexa, pois depende de uma mobilização social onde as pessoas participarão de forma efetiva e democrática na determinação, bem como na manutenção dos indivíduos arbóreos a serem inseridos nas praças (LACERDA et al., 2014). Abaixo se apresenta o mapa de variedade de espécies por praça.

Nota-se no mapa da Figura 5, que as praças Paulo Machado e do Ferro Velho apresentaram o maior índice de variedade de espécies. O resultado é positivo, tendo em vista que a maioria das praças apresenta boa variedade de espécies. A variedade de espécies nativas, que produzem flores vistosas, como por exemplo, as oitizeiras pode contribuir para uma satisfação psicológica dos cidadãos que moram na zona urbana (VOLPE-FILIK et al., 2007 apud BATISTEL et al, 2009). Em contraposição, a baixa diversidade nas demais praças estudadas é encarada como ponto negativo. A ocorrência de poucas espécies potencializa a ação de pragas tendo em vista que cada espécie apresenta mecanismos de resistências distintos, bem como a baixa estabilidade de tempo de floração, pois onde há maior número de espécies poderá ocorrer maior período de aparição de flores, que por sua vez, atenuam a estética da paisagem.

Dessa forma, percebeu-se que os aspectos técnicos que orientam a arborização das praças em Buritizeiro necessitam de revisão. Nesse sentido, sugere-se a utilização de equipe interdisciplinar, bem como, a informatização dos atributos referentes aos próximos indivíduos plantados, visando utilizar Geoprocessamento para reordenar de modo eficiente as futuras paisagens arbóreas da cidade em questão.
Geografia Ensino \& Pesquisa, v. 18, n.2, p. 109-122, maio/ago. 2014.

Fonseca, S. F. da; Santos, D. C. dos; Trindade, W. M. 
Figura 5-Mapa de Variedade de Espécies Arbóreas por praça sobrepostas a Planta Municipal.

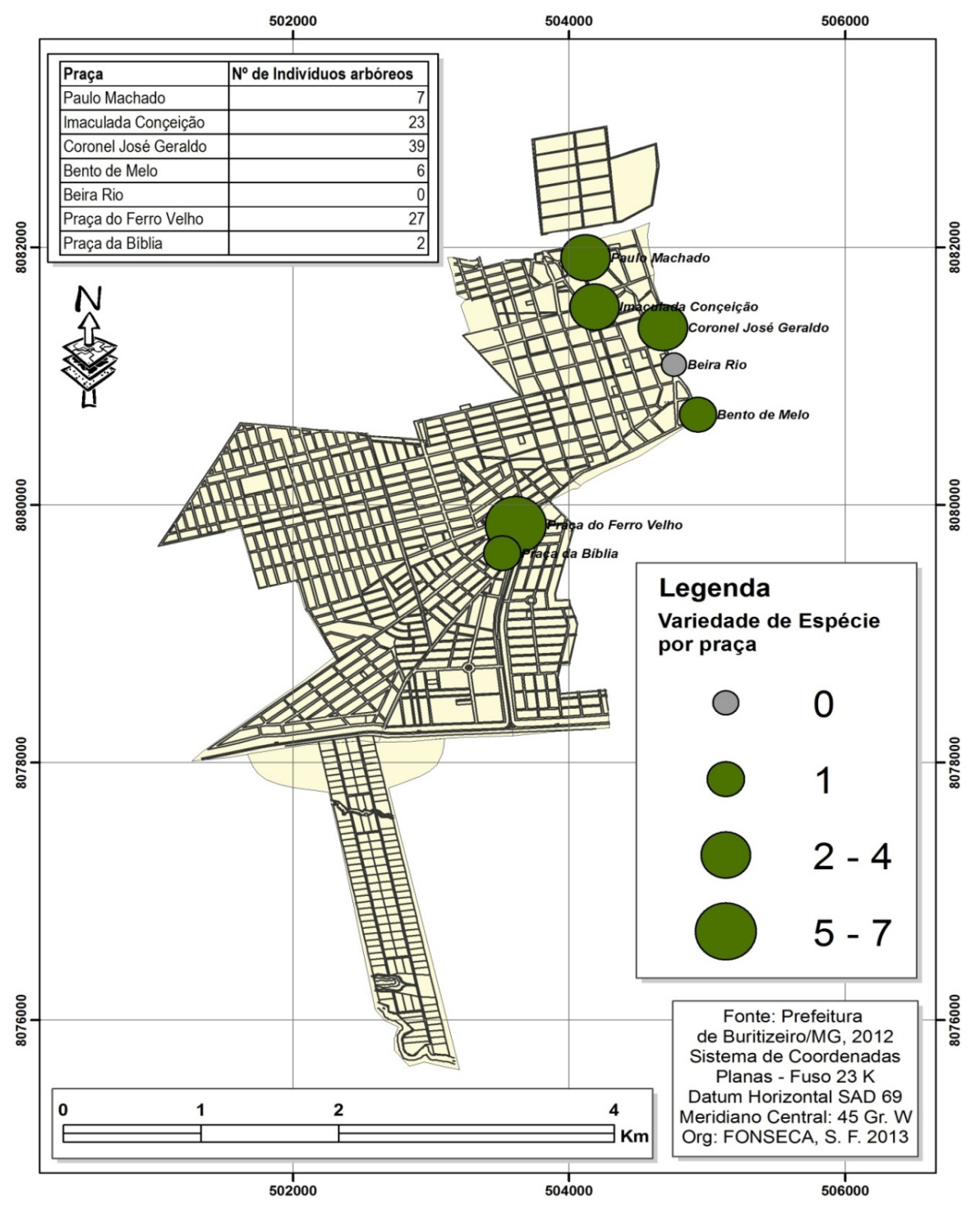

Fonte: organizado por FONSECA, S. F. (2013).

Diâmetro a altura do peito - DAP

O DAP é uma variável dendrométrica que permite inferir o volume cúbico dos espécimes mensurados. As variáveis, como DAP e CAP, quando analisadas para arborização urbana, não precisam ter valores exatos, uma vez que, para essa finalidade não se tem necessidade de determinação de volume, porém, há ressalva quando o objetivo do inventário é acompanhar o crescimento para volume (SILVA et al. 2007 apud LIMA NETO 2011).

Conforme Cabacinha e Castro (2010), a estrutura diamétrica corresponde ao histórico de uma comunidade vegetal podendo indicar equilíbrio ou desequilíbrio dos espécimes, bem como sua adaptação as mudanças no ecossistema. No entanto, em ambientes urbanizados, a vegetação

Geografia Ensino \& Pesquisa, v. 18, n.2, p. 109-122, maio/ago. 2014.

Técnicas de geoprocessamento aplicadas na classificação e distribuição das espécies arbóreas nas praças de Buritizeiro/MG possui comportamento diferenciado quando comparado com aquelas localizadas em áreas com menores interferências antrópicas.

$\mathrm{Na}$ área de estudo apenas duas praças apresentaram indivíduos com DAP $<5 \mathrm{~cm}$, nas demais todas as árvores estão acima do valor esperado para uma boa representatividade. No presente trabalho a aplicação das técnicas de geoprocessamento permitiu a geração de um mapa referente ao DAP. (Figura 6). 
Figura 6- Mapa de média geral de DAP. Neste, pode-se observar que as praças, Paulo Machado, Cel. José Geraldo e Imaculada Conceição apresentaram os maiores valores

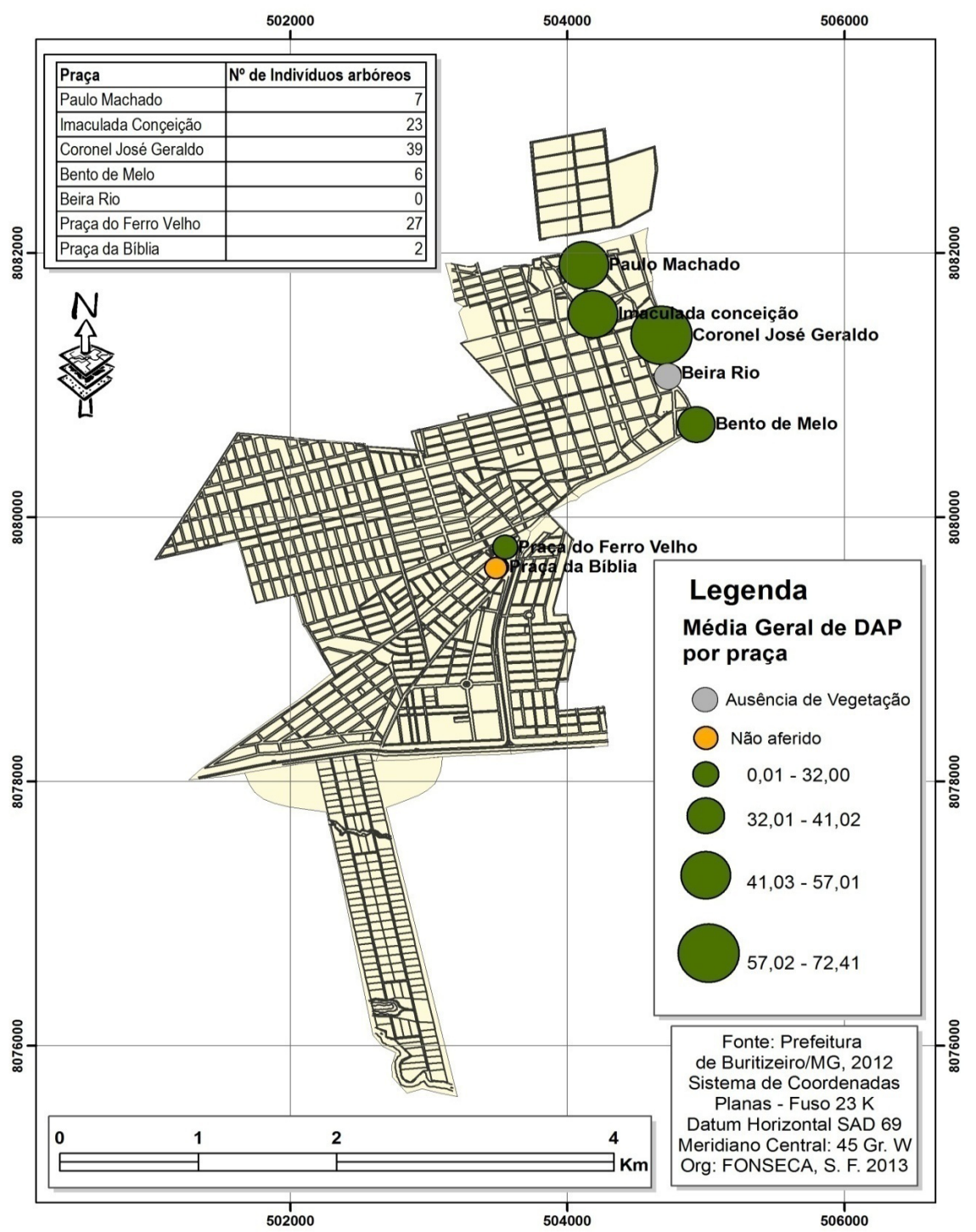

Fonte: organizado por FONSECA, S. F. (2013).

Situação fitossanitária

A saúde fitossanitária dos indivíduos arbóreos encontrados nas praças é uma variável que expressa a qualidade da paisagem em termos de beleza cênica, causando, de certa forma, desconforto visual quando a situação é classificada como ruim (BATISTEL et al., 2009; SCHUCH, 2006) . Como mencionado na metodologia, nesse trabalho foram utilizados os mesmos critérios estabelecidos por Schuch, (2006) para caracterizar tal variável. A Figura 7 mostra uma situação classificada com Razoável, onde notamos a intensa carga de liquens e parasitas no indivíduo arbóreo. A situação fitossanitária média de todas as praças estudadas pode ser visualizada no mapa (Figura 8).

No mapa, é possível verificar que as praças Cel. José Geraldo, Bento de Melo e do Ferro Velho são as que apresentam indivíduos com situação fitossanitária ruim. Nas praças, da Bíblia e Imaculada Conceição, por sua vez, não ocorreram nenhum indivíduo com a situação ruim. Os fatores condicionantes, que levam a uma classificação negativa quanto a situação fitossanitária dos indivíduos arbóreos podem estar associadas a podas drásticas, proximidade com a rede de distribuição de energia elétrica e presença de contaminantes no solo e no ar gerados pela dinâmica urbana (SCHUCH, 2006).

Geografia Ensino \& Pesquisa, v. 18, n.2, p. 109-122, maio/ago. 2014.

Fonseca, S. F. da; Santos, D. C. dos; Trindade, W. M. 
Figura 7 - Foto da situação fitossanitária comprometida com presença de liquens e fungos. Na mesma foto pode-se observar a ação de brocas no tronco da árvore (lado esquerdo do tronco) formando uma cavidade que põe o indivíduo em risco de queda e/ ou quebra do tronco. Praça cel. José Geraldo

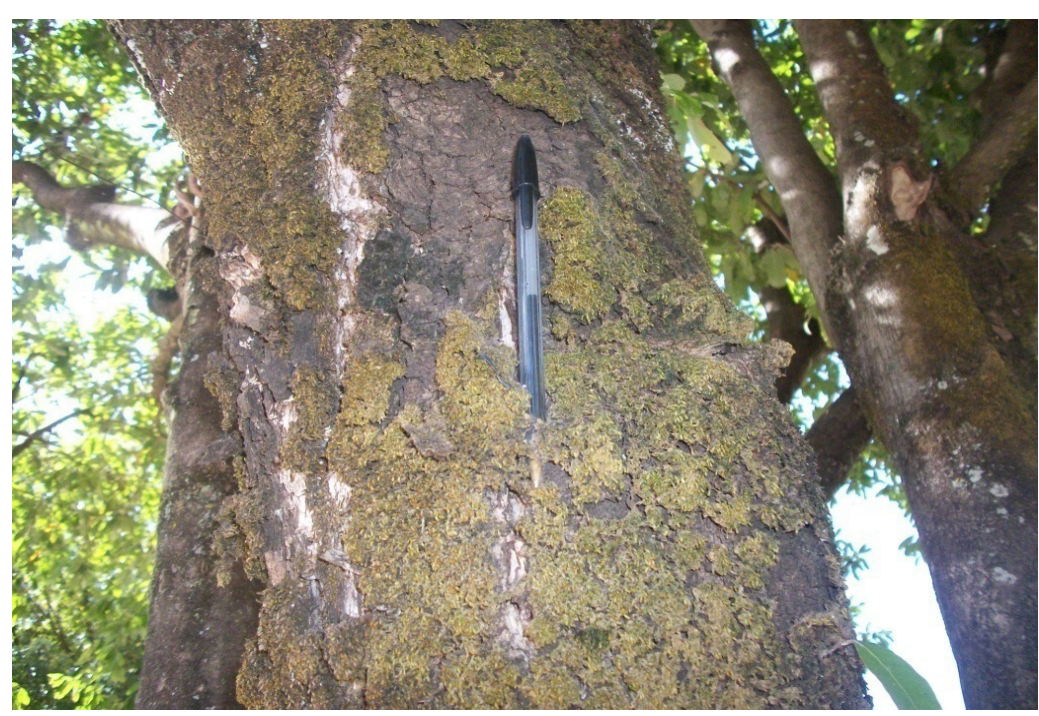

Fonte: fotografia de FONSECA, S. F. 2013.

Figura 8 - Situação fitossanitária média dos indivíduos arbóreos por praça. Classificação em Boa, razoável e ruim, notadamente cabe destacar a praça Bento de Melo.

Geografia Ensino \& Pesquisa, v. 18, n.2, p. 109-122, maio/ago. 2014

Técnicas de geoprocessamento aplicadas na classificação e distribuição das espécies arbóreas nas praças de Buritizeiro/MG

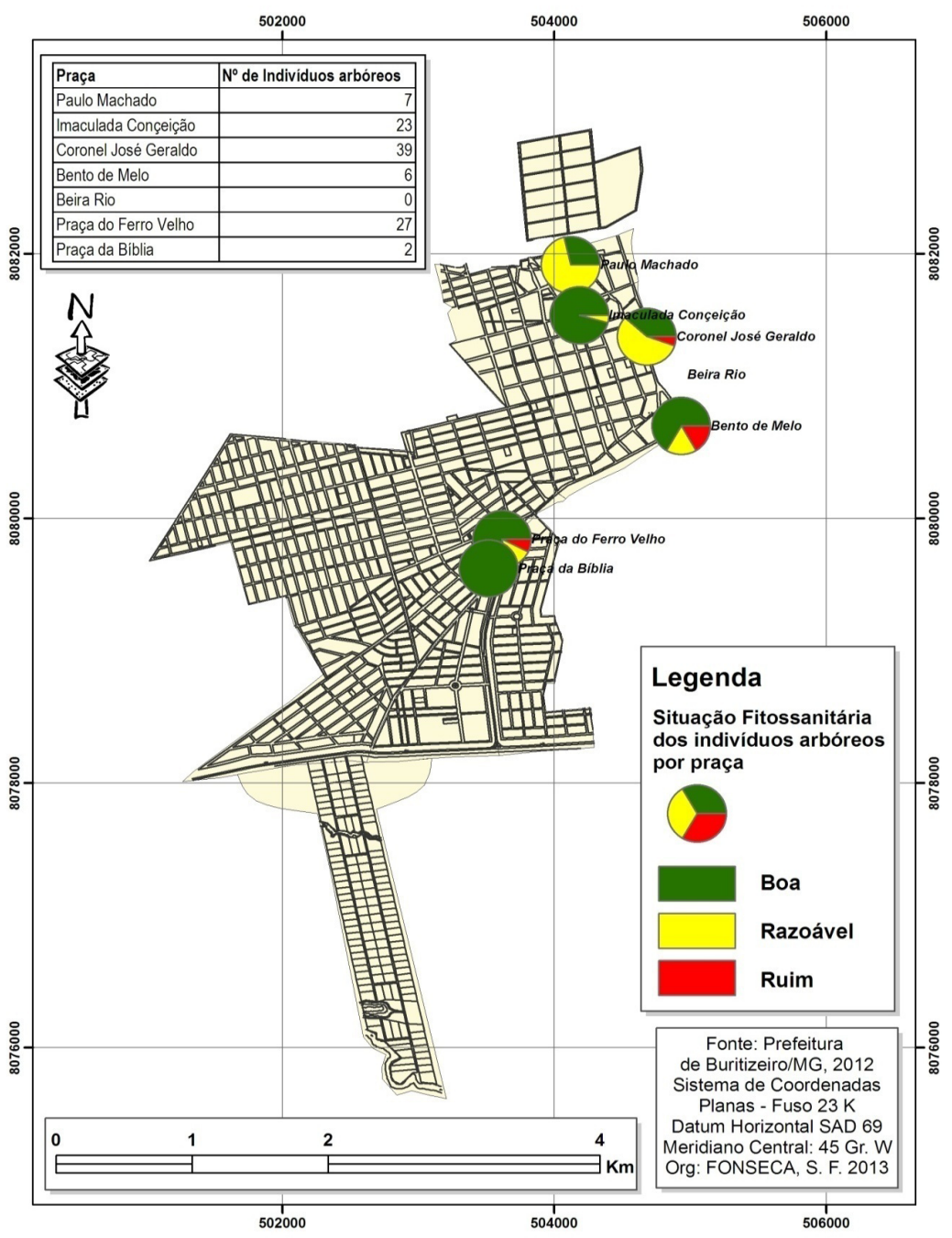

Fonte: organizado por FONSECA, S. F. (2013). 
Interferências na rede de distribuição de eletricidade

Conforme Mendonça et al, (2009) a rede de energia elétrica deverá ser implantada preferencialmente nas calçadas oeste e norte, e sob as árvores de pequeno porte. Nas calçadas leste e sul deverão ser plantadas árvores de porte médio, observando-se as dimensões da via pública e o paisagismo local. Esta distribuição procura otimizar a utilização do sol como forma de aquecimento.

O manual de arborização urbana deste município recomenda que: nas avenidas com canteiro central, o posteamento deve ser implantado nas calçadas laterais. O canteiro central deve ser arborizado, podendo ser utilizadas espécies de médio a grande porte (MENDONÇA et al. 2009).

Interferências no sistema de sinalização de trânsito

É importante observar que, nos aglomerados urbanos há uma série de variáveis que precisam ser consideradas nas tomadas de decisões, entre essas variáveis, é importante pensar nos aspectos futuros da arborização.

Conforme Mendonça et al., (2009) as árvores de porte médio não devem se localizar a uma distância inferior a $7 \mathrm{~m}$ das esquinas e das placas de sinalização de trânsito. Na Figura 9 é possível visualizar duas situações conflitantes, primeiro, pela localização em relação à esquina, e segundo em relação à placa de sinalização de trânsito.

Figura 9 - Situação conflitante na Praça Cel. José Geraldo. Observa a placa de sinalização de trânsito logo abaixo de uma Oitizeira.

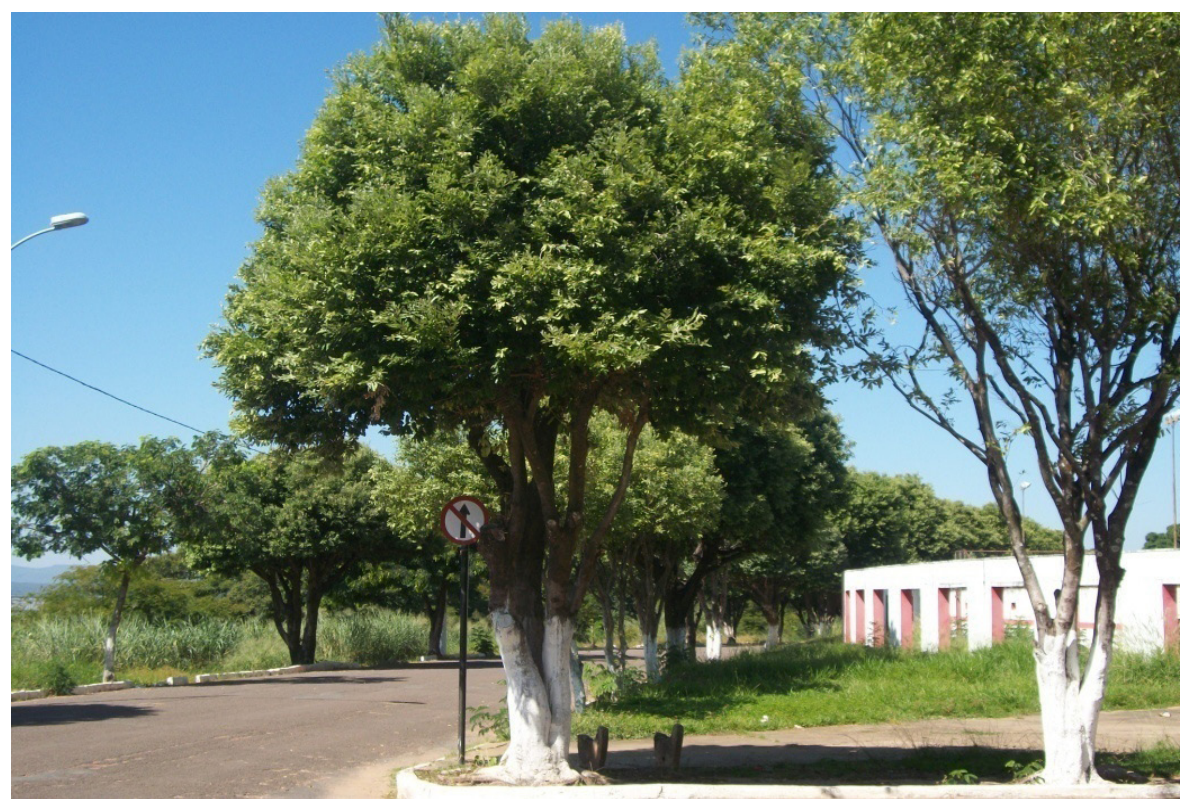

Fonte: fotografia de FONSECA, S. F. 2013.

Dentre todas as praças analisadas, a praça Cel. José Geraldo, foi a única que apresentou situação de conflito. (Figura 10). Essa situação tem causado sérios problemas para a cidade de Buritizeiro, devido a referida praça se localizar em frente ao prédio da Prefeitura Municipal, localidade de movimentação constante de veículos e pedestres.

Geografia Ensino \& Pesquisa, v. 18, n.2, p. 109-122, maio/ago. 2014.

Fonseca, S. F. da; Santos, D. C. dos; Trindade, W. M. 
Figura 10 - Mapa de Situação conflitante com sinalização de trânsito. Note que a praça Cel. José Geraldo apresenta conflitos relacionados a implantação de placas de sinalização em área arborizada.

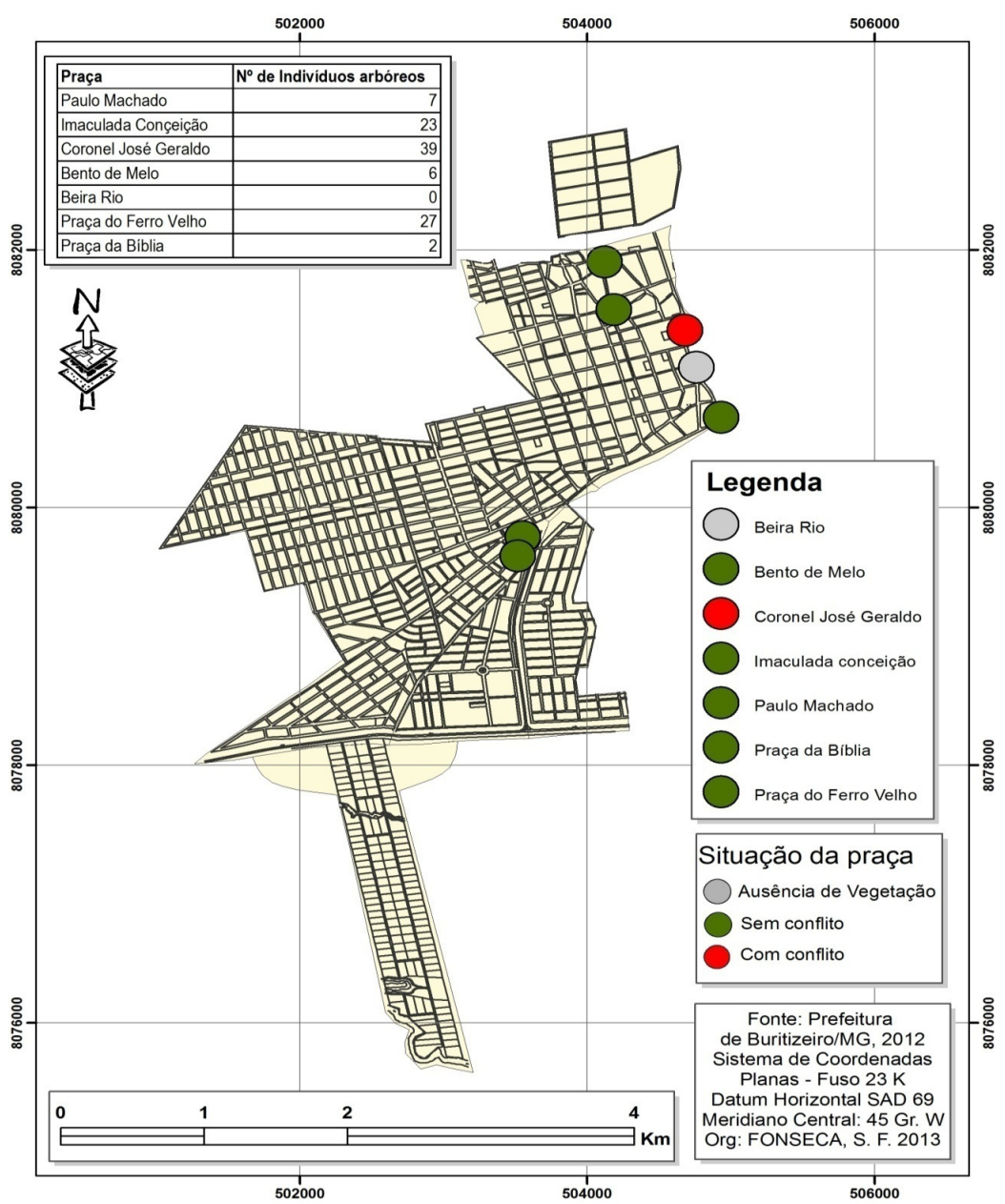

Fonte: organizado por FONSECA, S. F. (2013).

\section{Considerações finais}

A cidade de Buritizeiro possui arborização incipiente e, carente de melhorias no sentido de distribuição de espécies arbóreas e demais componentes da área urbana, tais como distribuição de energia elétrica, jardinagens nos canteiros centrais das vias e orientação das áreas destinadas a praças, o que pode ser fruto da ausência de um planejamento urbano consistente.

Os entraves relacionados à arborização das Praças, tais como: a escolha das espécies, o processo de manejo, a realização de podas orientadas, bem como uma infinidade de informações convergentes com as necessidades cotidianas, podem ser facilmente inseridas em um SIG e assim realizar uma análise temporal e espacial das mesmas. Fator que pode possibilitar maior eficiência no manejo da arborização bem como no acompanhamento dos espécimes plantados nas áreas verdes urbanas.

O presente estudo mostrou de forma integrada aspectos da arborização das praças em Buriti-

Geografia Ensino \& Pesquisa, v. 18, n.2, p. 109-122, maio/ago. 2014.

Técnicas de geoprocessamento aplicadas na classificação e distribuição das espécies arbóreas nas praças de Buritizeiro/MG zeiro, tais como baixa variedade de espécie por praça, DAP dos indivíduos arbóreos, Situação fitossanitária comprometida na maioria das praças permitindo aos gestores uma visualização geral do problema contribuindo de maneira mais eficaz na tomada de decisão.

Destaca-se como ponto positivo a baixa interferência no sistema de trânsito e a ausência geral de interferência na rede de distribuição de energia elétrica.

A praça Cel. José Geraldo apresentou dois pontos negativos. Situação fitossanitária com grande quantidade de indivíduos com nível razoável e conflito com sinalização de trânsito, vez que, alguns 
indivíduos, dessa praça não possuem distância significativa das calçadas e nem das esquinas, comprometendo a visibilidade dos transeuntes.

Para manter a situação fitossanitária equilibrada, necessita-se de atenção especial nas diversas fases da arborização, desde os plantios, tratando de diversificar os espécimes à supressão, quando se fizer necessária, desde que façam replantios.

Percebeu-se que o Geoprocessamento é uma janela de oportunidades para uma análise ambiental urbana integrada, pois possibilita, de maneira prática, análises que direcionam o planejamento urbano, bem como, que orientem a arborização das praças de forma consistente. No entanto, é necessário que haja políticas públicas voltadas para arborização das praças e informatização dos dados relativos às mesmas além de criação de uma gerência de Geoprocessamento para a cidade como alternativa inicial para nortear as atividades inerentes ao desenvolvimento de metodologias, que permitam interpretar o ambiente urbano e suas interfaces.

\section{Referências}

BAGGIO, H. 2002. Alterações na paisagem natural e agrícola do município de Buritizeiro -MG: implicações do plantio generalizado de pinus e eucaliptos no meio ambiente físico, biológico e socioeconômico. 149 p. Dissertação (Mestrado em Geografia). Instituto de Geociências - Universidade Federal de Minas Gerais - UFMG. Belo Horizonte.

BAENINGER, R. Cidades e Metrópoles: a desaceleração no crescimento populacional e novos arranjos regionais. in: XI Congresso Brasileiro de Sociologia, $1^{\circ}$ a 5 de setembro de 2003. UNICAMP, Campinas, SP. ANAIS...

BATISTA, J. L. F. et al. Manual De Campo: Inventário Florestal Contínuo da Floresta Comercial da Estação Experimental de Ciências Florestais de Itatinga/SP. Centro de Métodos Quantitativos do Depto. de Ciências Florestais, ESALQ, Universidade De São Paulo. 2008

BATISTEL, L. M.; DIAS, M. A. B.; MARTINS, A. S.; RESENDE, I. L. M. Diagnóstico qualitativo e quantitativo da arborização urbana nos bairros Promissão e Pedro Cardoso, Quirinópolis, Goiás. IN: Revista da Sociedade Brasileira de Arborização Urbana- REVSBAU. Piracicaba - SP, v.4, n.3, p.110 - 129, 2009

BRASIL, Instituto Brasileiro de Geografia e Estatístico-IBGE, 2010. Disponível em http:/ /www.ibge.gov. br/cidadesat/painel/painel.php?codmun=310940 Acessado em 22/10/2012.

BRITO, T. H. S. 2009. Correlação dos Aspectos Geológicos Com a Fitofisionomia da Mata Seca Nos Municípios de Buritizeiro, Ubaí e Jaíba-MG. (Monografia) - Departamento de Geografia. Universidade Estadual de Montes Claros-UNIMONTES. Pirapora-MG. 67p.

BURITIZEIRO - MG, Prefeitura Municipal de. 2012. Histórico da Estação Ferroviária Independência. SETEC - Secretaria de Educação e Cultura. Documentos Históricos.

CABACINHA, C. D., \& CASTO, S. S. Estrutura diamétrica e estado de conservação de fragmentos florestais no Cerrado Brasileiro. IN: Revista Floresta e Ambiente. 17 (1): 1 - 7. Julho, 2010.

CÂMARA, G; DAVIS, C; MONTEIRO, A. M; D'ALGE, J. C. Introdução à Ciência da Geoinformação. $2^{\circ}$ edição, (revisada e ampliada). São José dos Campos/SP: INPE - Instituto Nacional de Pesquisas Espaciais, 2001.

CETEC (FUNDAÇÃO CENTRO TECNOLÓGICO DE MINAS GERAIS). 2008. Mapa de solos do estado de Minas Gerais: escala 1:600.000. CETEC, Belo Horizonte/MG.

DANTAS, I. C. \& SOUZA, C. M. C. de. 2004. Arborização urbana na cidade de Campina Grande - PB: Inventário e suas espécies. IN: Revista de Biologia e Ciências da Terra. Volume 4 - Número 2 - $2^{\circ}$ Semestre.

FITZ, P. R. Geoprocessamento sem complicação. Oficina de Textos. São Paulo, 2010.

FLORENZANO, T. G. Iniciação em Sensoriamento Remoto. $3^{a}$ ed. Ampliada e atualizada. São Paulo. Oficina de Textos, 2011.

FONSECA, S. F. 2012. Geoprocessamento como ferramenta de análise da apropriação do espaço na porção sudeste: a área urbana de Buritizeiro/MG. IN: Anais... IV Encontro de Ciências Sociais do Norte de Minas. UNIMONTES - Universidade Estadual de Montes Claros/MG. 08 a 11 de agosto. Montes Claros/MG.

Geografia Ensino \& Pesquisa, v. 18, n.2, p. 109-122, maio/ago. 2014.

Fonseca, S. F. da; Santos, D. C. dos; Trindade, W. M. 
FONSECA, S. F. \& SANTOS, D. C. Diagnóstico de Degradação Ambiental da Vereda da Fazendinha na Região Sudeste do Sitio Urbano do Município de Buritizeiro-MG: ênfase na sedimentação, no desmatamento para pastagens e plantios inadequados. IN: Anais... VI Encontro Regional Povos do Cerrado, UNIMONTES - Universidade Estadual de Montes Claros/MG - 01 a 05 de Junho de 2011 ISSN 1981 - 306. Pirapora/MG.

FONSECA, S. F; SOUZA, F. C. R. Qualidade da Água de Superfície e Parâmetros Físico-químicos do Córrego das Pedras, Buritizeiro - MG. IN: Anais... XIII Congresso Brasileiro de Geoquímica/III Simpósio de Geoquímica dos Países do Mercosul. Gramado, RS. v. 9. Outubro, 2011.

FJP - Fundação João Pinheiro. Regiões Administrativas. Belo Horizonte, 1996.

FRANCO, V. S. de M. 2006. Gerenciamento da arborização na área do campus da UFMG utilizando ferramentas SIG. Monografia, (Especialização em Geoprocessamento). UFMG - Universidade Federal de Minas Gerais - Belo Horizonte/MG.

GAMA, M. G. C. C. 2006. Água, vereda, veredeiro: um estudo sobre as agriculturas camponesas e comercial, nas cabeceiras do Rio Formoso, em Buritizeiro-MG. Dissertação (Mestrado em Geografia). Universidade Federal de Uberlândia - UFU. Programa de Pós-Graduação em Geografia, 115 p.

HIGUCHI, N.; SANTOS. J.; LIMA, A. J. N. Biometria Florestal. Instituto Nacional de Pesquisas da Amazônia. Coordenação de Pesquisas em Silvicultura Tropical \&Laboratório De Manejo Florestal - LMF. Manaus, 2008.

KOPPEN, W. Climatologia. México. Fundo de Cultura Econômica. 1948.

LACERDA, A. C.; SANTOS, D. C.; MENDONÇA, G. L.; FONSECA, S. F.; 2014. Plano Municipal de Gerenciamento Integrado de Resíduos Sólidos - PMGRS. Prefeitura Municipal de Buritizeiro \& Serviço Autônomo de Água e Esgosto-SAAE. Documentos \& Trabalhos técnicos municipais.

LIMA NETO, E. M. de. 2011. Aplicação do sistema de informações geográficas para o inventário da arborização de ruas de Curitiba, PR. Dissertação (Mestrado em Engenharia Florestal) - Universidade Federal do Paraná, Setor de Ciências Agrárias, Programa de Pós-Graduação em Engenharia Florestal.

MACÊDO, B. R. M. de; LISBOA, C. M. C. A.; CARVALHO, F. G. de. Diagnóstico e diretrizes para a arborização do campus central da Universidade Federal do Rio Grande do Norte.IN: Revista da Sociedade Brasileira de Arborização Urbana - REVSBAU.Piracicaba - SP, v.7, n.1, P. 35-51, 2012

MENDONÇA, G. L. et al. 2009. Manual de orientação para manejo da Arborização urbana. Prefeitura Municipal de Buritizeiro - MG. SETEC - Secretaria de Meio Ambiente.Relatórios Técnicos.

PIVETTA, K. F. L. \& SILVA FILHO, D. F. Arborização Urbana. Boletim acadêmico série arborização urbana. UNESP/FCAV/FUNEP. Jaboticabal, SP - 2002.

ROSA, R. Introdução ao Sensoriamento Remoto. $7^{\mathrm{a}}$ ed. Uberlândia: EDUFU, 2009.

SCHUCH, M. I. S. 2006. Arborização Urbana: uma contribuição à qualidade de vida com uso de geotecnologias. Dissertação (Mestrado em Geomática). Universidade Federal de Santa Maria, Centro de Ciências Rurais, Programa de Pós-Graduação em Geomática.

TRINDADE, W. M. RIBEIRO, E. V. BAGGIO. H. HORN. A. H. O Grupo Mata da Corda na bacia do Rio Formoso e suas feições morfológicas correlatas. Anais...VI Simpósio Nacional de Geologia. Goiânia-6-10 de Setembro de 2006.

VIANA, V. M. F. C. 2006. Estudo Geológico Ambiental das Veredas do Rio Formoso no Município de Buritizeiro, Minas Gerais. Dissertação (Mestrado em Geologia) - Instituto de Geociências - Universidade Federal de Minas Gerais - UFMG. Belo Horizonte. 71p.

\section{Correspondência}

\section{Samuel Ferreira da Fonseca}

Geografia Ensino \& Pesquisa, v. 18, n.2, p. 109-122, maio/ago. 2014

Técnicas de geoprocessamento aplicadas na classificação e distribuição das espécies arbóreas nas praças de Buritizeiro/MG
E-mail: samuelsig@ymail.com

Recebido em 6 de janeiro de 2014.

Revisado pelo autor em 26 de julho de 2014.

Aceito para publicação em 26 de agosto de 2014. 